International Journal of Biology, Pharmaey and Allied Sciences (IJBPAS)

'A Bridge Betueen Caboratory and QRendo'

WwW.iibpas.com

\title{
A REVIEW ON BACTERIOCIN PRODUCED BY LACTIC ACID BACTERIA
}

\section{KAUR $\mathrm{S}^{1}$, UPADHAYAY $\mathrm{D}^{2}$, MARCHAWALA $\mathrm{F}^{2}$, BHATTACHARYA $\mathrm{I}^{2}$ AND ANDHARE $\mathbf{P}^{2 *}$}

1: Student, M. Sc. Microbiology, Parul Institute of Applied Sciences, Parul University, Post Limda, Waghodia, Gujarat, 391760

2: Assistant Professor, Parul Institute of Applied Sciences, Parul University, Post Limda, Waghodia, Gujarat, 391760

*Corresponding Author: E Mail: Dr. Prasad Andhare: prasad.andhare82145@paruluniversity.ac.in; Tel: $+918200614350$

Received $19^{\text {th }}$ Jan. 2021; Revised 22 ${ }^{\text {nd }}$ Feb. 2021; Accepted $20^{\text {th }}$ March 2021; Available online $1^{\text {st }}$ April 2021 https://doi.org/10.31032/IJBPAS/2021/10.4.1017

\begin{abstract}
Various Gram positive and Gram-negative bacteria are produced during growth, a specific protein component of either proteins or polypeptides, which have antibacterial properties and structures, called bacteriocins. Bacteriocins are highly comparable to antibiotics because of their similar properties but they are not. They differ from one another on the basis that the bacteria control their activity in the species of microorganisms associated with the productive species and especially in the species of the same species. Antibiotics, on the other hand, have a broader role and if the activity is restricted, they will not show any specific effect on the most intimate species. In addition, the bacteriocin is a protein composed of ribosomes and formed during the first phase of growth which is why they are called primary metabolites and antibiotics are more commonly called secondary metabolites. Among all the fine Gram bacteria, lactic acid bacteria (LAB) there, Lactobacilli have received the most attention at the moment, due to the production of bacteriocin. The use of Bacteriocins occurs mainly in the food industry. It is widely used as a natural food preservative. The use of Lactic acid bacteria and their metabolic products produced by them is generally considered safe (GRAS). Nisin is the only bacteriocin officially used in the food industry and its application has been accepted
\end{abstract}


worldwide. The use of bacteriocin is done in a completely pure form or it can also be done in an impure way or with the use of a product that is a pre-made product or original culture.

Keywords: Lactic acid Bacteria, Lactobacilli, Bacteriocins, Nisin

\section{INTRODUCTION}

Lactic bacteria are various group of genera that can be identified as Gram-positive, catalase negative, non-sporulating, nonpigmented mesophiles. The tolerant temperature is usually between 5 and $50^{\circ}$ $\mathrm{C}$, and the size of most species is about $30^{\circ}$ C. Standards vary, from cocci to long sticksi.e. rods. Although physically similar, there is a lack of DNA homology among them. They have no means of reducing nitrate, catalase assembly and assembly of cyto-chromes and other pigments. They also have a posh and flexible need for a variety of foods that fit the species [1]. Lactic acid is an organic compound produced as a result of fermentation metabolism by lactic acid bacteria. Many chemical reactions are involved within the chemical processes that take place in living systems. Among these, lactic acid is an important metabolite of an equally important process of energy delivery. Lactic acid can be an acid with the formula $\mathrm{CH}_{3} \mathrm{CHOHCOOH}$ and can be a natural colorless liquid [2]. It is a chemical that is used in many industries and used for commercial purposes. used for tanning leather, for making inks, solvents and lacquers. Lactic acid is added in addition to the acidification, flavor, $\mathrm{pH}$ buffering agent and also prevents spoilage in processed foods that are mainly caused by bacteria. Carboxylic acid esters are used in baking foods to make emulsify. Various compounds such as organic acid, diacetyl, peroxide and bacteriocin or bactericidal proteins are produced by lactic acid bacteria during carboxylic acid fermentation. The synthesis of lactic acid is usually done by two processes induced by synthesis by chemical and carbohydrate fermentation. Lactic acid bacteria have a strong antibody function against many microorganisms and bacteria that are responsible for food spoilage. In addition, some species may contribute to the preservation of ripe food by producing bacteriocins. Research into lactic acid bacteria has expanded over the decades to include the use of bacteriocin or products such as natural food preservatives [3]. Bacteriocins are composed of ribosomes, which release bioactive peptides or peptide complexes that usually contain $30-60$ amino acids and have bactericidal or bacteriostatic effects in some species. Lactic acid produces antibodies that are usually divided into two main groups: low molecular weight molecules $<1000 \mathrm{Da}$ and high molecular weight molecules $>1000$ 
Da, such as bacteriocins [4]. Bacteriocins come in many small cell peptides. it was also noted that the molecular size of reutericyclin cells is $3100 \mathrm{Da}$, which indicates that they form stable multimers in strong solutions, whether they are denaturing agents or organic solvents. Further purification is performed with chromatography with thin layers. Lactic acid is produced in boiled products by hydrolysis, biochemical metabolism, and microbial activity. Determination of lactic acid balance is important for mature products for technical, healthy, and nutritional reasons. Trimetric methods, gas chromatography, colorimetry and enzymatic methods of sampling techniques used to analyze 1of organic acid. However, because of its simplicity and speed of study, HPLC techniques are an effective method, requiring minimal sample preparation prior to separation and allows for complete determination of organic acid in the short term, having active peptides and has a bactericidal or bacteriostatic effect in some closely related species [5]. The term "bacteriocine" was first coined 50 years ago to describe the Gram-negative bacteriocin type colicin. However, a basic consideration of bacteriocin-mediated inhibition dates back more than 130 years ago when Pasteur and Joubert (1877) reported inhibition of Bacillus anthracis by bacteria isolated from urine samples.
Bacteriocin also known as proteinaceous compounds, kills closely related bacteria, but it is now well-known that bacteriocins may also be active throughout the body (broad spectrum) [6].

\section{Classification of Bacteriocin:}

As for the bacteriocin, which is produced by Gram-positive bacteria, those produced by lactic acid bacteria (LAB), including Lactococcus, Lactobacillus, Leuconostoc, Enterococcus, Pediococcus, Carnobacterium and a few 18 members of the genus Streptococcus, which is the main target. The condition of many of these manufacturers means that their peptides associated with them can be used in other ways, including food preservation, food safety in person and in medicine [7]. Lactococcus lactis produces Nisin A that is the most well-known of all bacteriocins, so an important interest in bacteriocin-related research could be traced back to the successful development of nisin from the initial recognition of the L. lactis inhibitory activity against Lactobacillus bulgaricus, by exercising its regulatory license for use as a food bio-agent. Because of the extensive information on LAB bacteria, differentiated systems are proposed that are widely used in other Gram-containing bacteria [8].

Classification of Bacteriocins from Gram-Positive Bacteria: 
Early attempts to differentiate LAB bacteriocins include placing individual bacteriocins in one of eight groups that support their temperature resistance, handling distance, trypsin sensitivity and therefore the rate of reactivation between different bacteriocin and binding compounds. This method was obsolete by Klaenhammer (1993), who grouped the bacteriocin into different subgroups. This classification makes sense for all subsequent classification of bacteriocin bacteria that are naturally gram-positive bacteria. There are 4 classes of bacteriocin as follows:

Class I or lantibiotic: Well defined as small membrane-acting peptides $(<5 \mathrm{kDa})$ that contain the amino acids lanthionine or bmethyl lanthionine (hence the name lantibiotic) and aqueous residues. Nisin is the most visible of the Class I bacteria.

Class II: defined as a relatively low temperature non-lanthionine containing active membrane peptides characterized by the presence of the Gly-Gly processing site prior to bacteriocin, the presence of amphiphilic fractions with varying degrees of hydrophobicity and moderate to high temperature resistance. These were divided into three groups:

1.Subclass IIa: Listeria-acting peptides have a consistent sequence in the $\mathrm{N}$ terminal of Tyr-Gly-Asn-Gly-Val-XaaCys-
2. Subclass IIb: Poration structures consisting of two peptides that make up the active protein

3. Subclass IIc: Cell peptides that require reduced cysteine residues for activity

Class III: Large proteins with a temperature label, usually with enzymatic activity.

Class IV: Complex Proteins Containing Lipid or Carbohydrate Particles (MC Rea et al.)

For example, SapB, AMf and SapT are produced by Streptomyces coelicolor [9].

\section{Important Bacteriocin:}

The bacteriocin nisin is tested as a phase-Ia or lantibiotic bacteriocin and is the most important bacteriocin. Nisin is licensed as a preservative food (E234) and is labeled as safe by the Joint Food and Agriculture Organization / World Health Organization (FAO / WHO). , Z, F, and the alphabet produced by Lactococcus lactis and nisins $\mathrm{U}, \mathrm{U} 2, \mathrm{P}$, and $\mathrm{H}$ by other eubacterium species [10]. The most commercially available formula that can be used as a food preservative is Nisaplin TM, which contains the active ingredient nisin A $(2.5 \%)$ and various ingredients such as $\mathrm{NaCl}$ and non-fat milk. Nisin has antibacterial properties against various gram-positive microorganisms, as well as function, diseases such as bacteria and cocci, so the reproductive structure forms microorganisms, true bacteria and eubacteria. One of the first uses of nisin 
was to prevent the late processing of cheese caused by eubacteria spp. The wide range of restrictions associated with nisin includes the function itself. Therefore, in farm diets that require activity in relation to fermentation processes, the use of nisin imposes an extreme limit. the alternative consists of using different bacteria that have a specific function very differently. As a result, there has been a remarkable interest within the search for new bacteriocins with a high diversity of therapeutic drug functions, stability in many diets, heat tolerance, and resistance to chemical process enzymes [11].

\section{Applications of Bacteriocins:}

In modern times, bacteria have been widely used in the field of food preservation. Bacteriocins are widely used in the food industry especially in dairy products, egg, vegetables and meat. Among the LAB bacteria nisin A and its natural variety of nisin $\mathrm{Z}$ have been proven to be extremely effective against microbial agents that cause food poisoning and spoilage [12]. Many conservative methods have been used to prevent food poisoning and bacterial spoilage. Some of these methods are heat treatments that include pasteurization, sterilization, $\mathrm{pH}$ and lowering water efficiency and adding protective properties such as antibiotics, other organic compounds such as propionate, sorbate, benzoate, lactate, and acetate. Although these methods are very effective, there is an increase in demand for natural and microbiologically safe products that give consumers higher health benefits [13]. Bacteriocin can be used either in pure form or in impure form or in the use of a pre-fermented product in the form of a bacteriocin produced as an ingredient in food processing or in combination with a bacteriocin-producing type. . This method may not be financially viable if used alone, but at low doses and combined with other treatments such as bacteriocins can be very effective. Besides bacteria can be combined with other antimicrobial compounds such as sodium acetate and sodium lactate that increase bacterial resistance [14]. Bacteriocin can be used to improve the quality of food and nerve structures, for example; an increase in the rate of proteolysis or prevention of gas-induced dehydration in cheese. One use of bacteriocin packaging is bioactive, a process that can protect food from external contamination. In the event of food spoilage in the refrigerator it usually starts with an increase in microbial growth that supports the attractive use of bacteriocins used in mixing and packaging to improve food safety and shelf health [15].

\section{Purification and characterization of bacteriocin:}

Lactic acid bacteria need MRS medium for growth. Isolation of lactic acid bacteria is 
mostly done by first performing serial dilutions followed by spread plate and then pour plate method. Identification of various lactobacillus species is done by standard morphological, cultural and biochemical reactions.

Trimetric methods, gas chromatography, colorimetry, and enzymatic methods of sampling techniques are used to analyze bacteriocins. However, as a result of simplicity and speed of analysis, ammonium sulphate precipitation followed by dialysis and HPLC techniques are an attractive and highly effective method, requiring minimal sample preparation before separation and allowing for uniform determination of bacteriocins in a short period [16].

Further, for the characterization purpose, the molecular weight of bacteriocins is determined by the SDS-PAGE technique. The optimum $\mathrm{pH}$, temperature, metal ion effects are normally observed for the active functioning of bacteriocins [16].

\section{Advantages and disadvantages of}

\section{Bacteriocin:}

Advantages:

Bacteriocins have many benefits. Production strategies are many and varied. At the industrial level, the cost of producing bacteriocins is reduced by the month and may be lower than the cost of producing antibiotics. It is possible to use the bacteria present in our intestinal tract to produce bacteria in the stomach and to treat other bacterial infections in the gut. Furthermore, the proposed solution for the drug-resistant problem is not only dependent on the use of a single bacteriocin but on the composition of a combination of several bacteriocins. There is a chance that the way of escape and resistance to multiple drugs can be created against different bacteriocins is much lower than fighting a single antibiotic. By using 'bacteriocin cocktails' with completely modified and specialized mechanisms, it will kill only one bacterium which does not mean that any resistance will develop in a relatively short time [17].

\section{Disadvantages:}

The worst thing about bacteriocins is their protein base. Initially, they are victims of protease, a protein enzyme that breaks down other proteins. Second, by regulating certain bacteria in the human body, the immune system can respond. Although it works with low concentration, bacteria with low vivo viability, are at risk of being degraded by proteolytic enzymes. Another major problem is the possibility of mass production, and with these key factors their current clinical applications are limited [18].

\section{CONCLUSION}

The review highlights the differentiation and formation of $\mathrm{LAB}$ producing bacteriocin-derived organic foods and 
tested bacteriocin production, from which two bacteriocinogenic species are commonly identified and selected for study, namely Lactobacillus species called $L$. plantarum and L. fermentum. The bacteriocin which are produced by $L$. plantarum and L. Fermentumexhibits a variety of visuals. The ability of the above bacteriocin to block viruses like E. Coli, $S$. aureus, S. typhi, Pseudomonas and Klebsiella make it especially important for processed foods when there is a risk of multiple food infections. Their antagonistic properties are allowed in low $\mathrm{pH}$, unmixed acid and production of low and secondary antimicrobial metabolites. The antimicrobial effect used by LAB is the production of lactic acid and a reduction in $\mathrm{pH}$, diacetyl, hydrogen peroxide, fatty acids, aldehydes and other compounds. Many LABS are resistant to antibiotics. UV-exposed bacteriocin samples increase bacteriocin production. This is due to the effect of UV on the slope of the cell membrane. This bacteriocin quality makes it great for used food stuffs when high temperatures are used. The number of chromatographic steps differs by three or more, because the bacteriocin in the present study has the effect that the antibacterial activity is obtained after a simple exposure to ammonium sulfate from a multicolored fluid containing cells. Bioautography on thin layer chromatograms, a method previously used to detect anti-bacterial and antifungal agents for the control of pathogens was useful to reveal in the active component. Studies confirm that the isolated species of Lactobacillus are similar to the specific process used as a probiotic. Bacteriocins are mainly produced by $L$. plantarum and L. fermentum exhibits outstanding antimicrobial properties, heat resistance and acid tolerance indicating strong probiotic potentials so these isolates can be used to protect and develop intestinal flora and provide health benefits to consumers.

\section{ACKNOWLEDGEMENT}

It is our privilege and honour to express our sincerest gratitude to the Parul University, Vadodara, Gujarat for providing me all the necessary support and facilities including state of the art infrastructural facilities with advanced technological scientific laboratories and everything else that was required to carry out this work.

\section{REFERENCES}

[1] Saranya S. and Hemashenpagam N., International Journal of Microbiology Research,ISSN: 0975-5276 \& E-ISSN: 0975-9174, Volume 5, Issue 1( 2013), pp.-341348.

[2] Brookes R.M. and Buckle A.E. (1992), The Lactic Acid Bacteria, 1, Elsevier Sci. Pub., London. 
[3] Ogunbanwo S., Sanni A. and Onilude A. (2003) Afr. J. Biotechnol., 2(7), 179-184.

[4] Piard J.C. and Desmazeaud M. (1991) Lait, 71, 525-541.

[5] Brook T.M.T and Madigan (1991) Host-microbe Relationships and Disease Processes in Biology of Microorganisms., 6th ed. Prentice Hall Publicity Inc., 379-380

[6] Prescott M. Harley and Kelvin O. (2005) Microbiology, McGraw Hill Inc. International ed., 511-517.

[7] Narayanan N., Roychoudhury and Srivastava A. (2004) Elec-tronic Journal of Biotechnology, 7(1).

[8] Datta R. (1995) FEMS Microbiol. Rev., 16, 221-231.

[9] Zhennai Y. (2000) Antimicrobial Compounds and Extracellular Polysaccharides Produced by LAB: Structure and Properties, Academic Dissertation, Department of Food Technology, University of Helsinki, 61.

[10] Oyetayo V.O., Adetuyi F.C. and Akinyosoye F.A. (2003) Afr. J. Biotech. 2, 448-452.

[11] Brink ten B., Minekns M., Vander Vossen, Leer R.J. and Huis J.H.J. (1994) J. Appl. Bacteriol., 77, 140148.

[12] Aly Savadogo., Cheik A.T., Ouattara Imael, Bassole H.N., Al- fred S. Traore (2004) Pakistan Journal of Nutrition, 3(3), 174179.

[13] Bacteriocins Produced by Lactic Acid Bacteria A Review Article M. P. Zacharof and R. W. Lovittb, Multidisciplinary Nanotechnology Centre, Swansea University, Swansea, SA2 8PP, UK b College of Engineering, Multidisciplinary Nanotechnology Centre, Swansea University, Swansea, SA2 8PP, U

[14] Garneau S., Martin N.I. and Vederas J.C. (2002) Biochimie, 84, 544-592.

[15] Larsen A.G., Vogensen F. and Josephsen J. (1993) J. of Appl. Microbiology, 75(2), 113-122.

[16] Axelsson L. (2004) Lactic Acid Bacteria: Microbiological and Functional Aspects. 1-66.

[17] Savadogo A., Ouattara Cheik A.T., BassoleImael H.N and Traore S.A. (2004) Pak. J. Nutr., 3(3), 174-179.

[18] De Man J.C, Rogosa M., Sharpe M.E. (1960) J. Appl. Bacteriol., $23,130-135$. 